\title{
USER CENTRIC NeTWORK SELECTION IN WIRELESS HETNETS
}

\author{
L.Nithyanandan ${ }^{1}$, V.Bharathi ${ }^{2}$ and P.Prabhavathi ${ }^{3}$ \\ 1,2,3 Department of Electronics and Communication Engineering, \\ Pondicherry Engineering College, Puducherry, India \\ nithi@pec.edu \\ bharathimedrediffmail.com \\ prabhatechepec.edu
}

\begin{abstract}
The future generation wireless networks are expected to beheterogeneous networksconsisting of UMTS, WLAN, WiMAX, LTE etc. A heterogeneous network provides users with different data rate and Quality of Service $(Q o S)$. Users of future mobile networks will be able to choose from different radio access technologies. These networks vary widely in service capabilities such as coverage area, bandwidth and error characteristics. Network selection is a challenging task in heterogeneous networks and will influence the performance metrics of importance for both service provider and subscriber.This paper analysesuser centric network selection based on QoE (Quality of Experience) which include both technical and economical aspects of the user. WLAN-WiMAX-UMTS networks are integrated and the network selection for the integrated network is performed using game theory based network selection algorithm.
\end{abstract}

\section{KEYWORDS}

UMTS, WLAN, WiMAX, QoS, QoE and Heterogeneous network

\section{INTRODUCTION}

There is a rapid development in the wireless communication nowadays because there is an increase in number of mobile and internet users. One such new technology is the heterogeneous network which refers to the integration of different Radio Access Technology (RAT) such as WLAN, WiMAX, UMTS etc. These wireless networks differ in its bandwidth, coverage area, data rate, mobility, technology etc. WLAN network is basically 802.11 standardwhich provides less coverage and high data rates (54Mbps). WiMAX is 802.16 standard with data rates up to $75 \mathrm{Mbps}$ and coverage nearly $30 \mathrm{Km}$. UMTS is $3 \mathrm{GPP}$ standard which offers less data rate (2Mbps) and more coverage.Heterogeneous network provides benefits such as seamless connectivity, ubiquitous availability of multimedia services and effective utilization of available bandwidth to meet user requirements. In a wireless environment user's mobility, characteristics and availability of a network will change in time. So, the mobility management process considers the dynamic reselection of network as its major task.Network selection is necessary when users want to migrate between heterogeneous networks. Hence multi mode mobile terminal is used to select a network from the converged network.

Network selection is a quite difficult process in wireless environment since network condition varies randomly based on variation in user demands, random activity of users and vagueness of system parameters. In case of network centric approach, base station consists of a centralized controller which admits the user to a particular network and allocates bandwidth to the user to maximize network utility. The user's needs and optimum results are not achieved through this approach. Hence, to have a better performance, network selection can be done using user centric approach. In user centric approach, game theory based network selection algorithms are 
International Journal of Wireless \& Mobile Networks (IJWMN) Vol. 5, No. 3, June 2013

implemented at the user terminal. Future heterogeneous network will be consisting of different RANs at same place and network conditions vary according to channel condition,random requirement of users etc. In this realistic environment network selection using Game theory produces optimum result for users.

The rest of this paper is structured as follows. Section 2 gives the literature survey. Network selection process is explained in section 3. Section 4 describes the network selection decision making. Mapping of game theory to network selection is given in section 5. Section 6 explains the simulation results and finally section 7 concludes the paper.

\section{LITERATURE SURVEY}

J.Park, et al., [1] has proposed the user subscription dynamics, revenue maximization and equilibrium characteristics in two different markets (i.e., monopoly and duopoly). A fuzzylogic-based multiple-criteria decision making system to perform access network selection in a heterogeneous network environment is described in [2]. A simple policy enabled handoff across heterogeneous wireless networks is presented in [3], which allows users to express policies which selects best wireless network at any moment, and that makes trade-offs among network characteristics and dynamics such as cost, performance and power consumption.A networkselectionstrategy that only considers mobile users power consumption was introduced by M.Namet.al [4]. Another network selection algorithm was proposed by Q.Y.Songet.al [5] in which Analytical Hierarchy Process (AHP) and the Grey Relational Analysis (GRA) were discussed. The AHP algorithm divides the complex network-selection problem into a number of decision factors, and the optimal solution can be found by integrating the relative dominance among these factors. The GRA was also proposed for selecting the best network for a mobile user. This mathematical network selection model is suitable for static environment. Later in 2012 Manzoor Ahmed Khan et.al,[6] introduce da dynamic and uncertain environment for network selection where the users and operators have only a numerical value of their own payoffs as information, and constructed various heterogeneous COmbined fully Distributed Payoff and Strategy Reinforcement Learning (CODIPAS-RL) in which the users try to learn their own optimal payoff and their optimal strategy simultaneously. In [6] Bush Mosteller based CODIPAS-RL for interworking two networks is discussed. In this paper Bush Mosteller and less iterative Boltzmann-Gibbs CODIPAS-RL are discussed and it is implemented in three network interworked architecture simulated using OPNET.

\section{Network Selection Process}

Network selection process is defined as the process of selecting a specific network from the converged network which meets the user's requirements. To introduce the concept of Always Best Connected (ABC) anytime and anywhere, network selection mechanisms are facilitated in heterogeneous networks. Different Radio Access Networks (RAN) differs in coverage, data rate, QoS, pricing scheme etc., hence it is difficult for a user to select a particular network [7]. From the user's perspective, the variety of portable devices (such as smart phones, net books, or laptops) with support for multiple radio network interfaces, enable the option of connecting to the Internet anywhere and anytime. Users are able to freely migrate from one Radio Access Technology (RAT) to another or from one service provider to another. A network selection decision is made at call setup and subsequently the decision is re-made in the case of a handover trigger. The major phases in network selection process are Monitoring, Network selection and Call setup. In monitoring phase the mobile terminal monitors the network conditions, lists the available RAN's and predicts the characteristics of each RAN. By using these monitored data the mobile terminal triggers a Hand Off $(\mathrm{HO})$ decision. 
In network selection phase network selection process is initiated either by automatic trigger for $\mathrm{HO}$ for existing call or by a request for a new connection [8]. The best network is decided based on decision criteria provided by the device, application and monitoring process. When the target network is selected the call is set up on the candidate network. But conventionally this decision was made by network operators mainly based on Received Signal Strength. When the target network is selected, the connection set up on the target candidate network is executed. But in case of an existing network connection, HO is executed and the original connection is removed and the call is re-routed to the new connection. If first choice network is unavailable, then the next listed candidate is chosen as target network. Connection setup and connection release are handled by Mobile Internet Protocol Version 6.

\section{NETWORK SELECTION DECISION MAKING}

Every decision making mechanism requires essential and relevant input information in order to choose the best network [9]. The decision criteria that may be used in the network selection process are network metrics, device related information, application requirements and user preferences. Network metrics includes information about the technical characteristics or performance of the access networks such as technology type, coverage, security, pricing scheme, monetary cost, available bandwidth, network load, latency, Received Signal Strength, blocking probability, network connection time, etc. Device related information refers to information about the end-users' terminal device characteristics like supported interfaces, mobility support, capacity, capability, screen-size and resolution, location-based information, remaining battery power, etc. Application requirement refers to information about the requirements (minimum and maximum thresholds) needed in order to provide a certain service to the end user: delay, jitter, packet loss required throughput, Bit Error Rate, etc. User preferences comprise information related to the end-users satisfaction such as budget (willingness to pay), service quality expectations, energy conservation needs, etc. The user preferences play an important role in the decision mechanism and they may be used to weight the other parameters involved.

\section{MAPPING OF GAME TheORY TO NeTWORK SElection}

Game theory is a mathematical tool used in understanding and modelling competitive situations. In the wireless environment, game theory has been used in order to solve many distributed power control, resource management and dynamic pricing related problems[10].The main components of a game are: the set of players, the set of actions, and the set of payoffs. The players seek to maximize their payoffs by choosing strategies that deploy actions depending on the available information at a certain moment. Each player chooses strategies which can maximize their payoff. The combination of best strategies for each player is known as equilibrium. The mapping of game theory to network selection is given in Table 1.

Table 1. Mapping of game theory to network selection

\begin{tabular}{|l|l|}
\hline \multicolumn{1}{|c|}{ Game Component } & \multicolumn{1}{c|}{ Network Selection Environment Correspondent } \\
\hline Players & The agents who are playing the game : Users or networks \\
\hline Strategies & $\begin{array}{l}\text { A plan of actions to be taken by the player during the game: available/ } \\
\text { requested bandwidth, subscription plan, offered prices, available APs. etc. }\end{array}$ \\
\hline Payoffs & $\begin{array}{l}\text { The motivation of players represented by profit and estimated using utility } \\
\text { functions based on various parameters: monetary cost, quality, network load, } \\
\text { QoS, etc. }\end{array}$ \\
\hline Resources & $\begin{array}{l}\text { The resources for which the players involved in the game are competing: } \\
\text { bandwidth, power, etc. }\end{array}$ \\
\hline
\end{tabular}




\section{NETWORK SELECTION AlgORITHMS}

There are different strategies in network selection such as select the economic RAN, random network selection, select the preferred operator's network. But these strategies do not provide optimum results in a dynamic wireless network. An intelligent approach for network selection provides optimum results. Hence, to get optimum results network selection algorithm based on game theory was introduced[11]. COmbined and fully Distributed Payoff and Strategy Reinforcement Learning (CODIPAS-RL) were introduced in [6]. In this paper UMTS-WIMAXWLAN interworked environment is simulated. Bush-Mosteller based and Boltzmann-Gibbs based CODIPAS-RL is implemented for UMTS-WIMAX-WLAN interworked environment.

\subsection{Bush Mosteller based CODIPAS-RL}

Bush Mosteller based CODIPAS-RL is a stochastic model of reinforcement learning where users decide which action to take stochastically: each user's strategy is defined by the probability of undertaking each of the two actions available to them. After every user has selected an action according to their probability, every user receives the corresponding utility and revises their strategy $[6,11,12]$. The action of each user is determined based on (1)

$x_{j, t+1}\left(a_{j}\right)=x_{j, t}\left(a_{j}\right)+\lambda j S_{j, t}\left(1-x_{j, t}\left(a_{j}\right)\right)$

Where $\lambda_{j}$ is the user $j$ 's learning rate $(0<\lambda<1)$ and $S_{\mathrm{j}, \mathrm{t}}$ denotes stimulus of user which is given in (2) and its values ranges from $[-1,1]$. When stimulus magnitude or learning rate increases, then the change in probability also increase.

$S_{j, t}=\frac{u_{j, t}-M_{j}}{\sup _{a}\left|U_{j}(a)-M_{j}\right|}$

where $u_{j, t}$ denotes the perceived utility at time $t$ of player $j$ and $M_{j}$ is an aspiration level of player $j$. The payoff estimation for the experimented actions by the users is given in the eq. (3).

$\hat{\mathrm{u}}_{j, t+1}\left(a_{j}\right)=\hat{\mathrm{u}}_{j, t}\left(a_{j}\right)+v(t) *\left(u_{j, t}-\hat{\mathrm{u}}_{j, t}\left(a_{j}\right)\right.$

Bush Mosteller based CODIPAS-RL considers present action of user $j$ as well as the actions of other users. So it requires more memory and processing time is also high. Hence the number of iterations or time required for network selection process is more.

\subsection{Boltzmann-Gibbs based CODIPAS-RL}

Since Bush Mosteller based CODIPAS-RL takes more number of iterations for network selection, Boltzmann-Gibbs based CODIPAS-RL was used because it considers the previous action and present action of user $j$ alone and requires less memory. So, less number of iterations only are required in this algorithm [13, 14].The action of the user is based on Boltzmann distribution which is given in $[6,11]$ as

$B_{j, \in}\left(\hat{\mathrm{u}}_{j, t}\right)\left(a_{j}\right)=\frac{e^{\frac{1}{\epsilon_{j}} \hat{\mathrm{u}}_{j, t}\left(a_{j}\right)}}{\sum_{a^{\prime}{ }_{j} \in A_{j}} e^{\frac{1}{\epsilon_{j}} \hat{u}_{j, t}\left(a^{\prime}{ }_{j}\right)}}, a_{j} \in A_{j}, j \in K$ 
International Journal of Wireless \& Mobile Networks (IJWMN) Vol. 5, No. 3, June 2013

Where $\frac{1}{\epsilon_{j}}$ denotes the rationality level of the user $j . \hat{\mathrm{u}}_{j, t}$ denotes the estimated payoff of user $j$ at time $t$ and $a_{j}$ denotes the action of user $j$ at time $t$. Based on action of user in (4), the payoff for each user is calculated using eqn. (5).

$\hat{\mathrm{u}}_{j, t+1}\left(a_{j}\right)=\hat{\mathrm{u}}_{j, t}\left(a_{j}\right)+v(t) *\left(u_{j, t}-\hat{\mathrm{u}}_{j, t}\left(a_{j}\right)\right.$

The steps for selecting a network are given as follows:

Step 1: Assume users are initially connected to a network and calculate the payoff in current network

Step 2: Check for the alternate networks where users can connect

Step 3: Determine the payoff and action of the users based on Boltzmann-Gibbs CODIPAS-RL

Step 4: Determine Network Selection Probability (NSP) based on the action of users

\section{SiMUlation RESUltS}

For effective network selection process three networks such as WLAN, WiMAX and UMTS are integrated using OPNET modeller [15] and the network selection process is carried out for users using MATLAB.Fig.1 shows the architecture of WLAN-UMTS-WiMAX integration. The architecture is based on hybrid coupling in which the data packets between WLAN and WiMAX reaches the UMTS network directly through Gateway GPRS Support Node (GGSN) or through the IP core network based on data type(real time or non real time). The IEEE (WLAN, WiMAX) and 3GPP (UMTS) networks are integrated using IMS (IP Multimedia Subsystem) which is based on SIP (Session Initiation Protocol) and terminal mobility is provided using MIPV6. SIP is an application layer protocol which is used to establish, maintain and terminate the session. The basic components of SIP are P-CSCF (Proxy Call Session Control Function), I-CSCF (Interrogating Call Session Control Function) S-CSCF (Serving Call Session Control Function) and Home Subscriber Station (HSS). Within the coverage of UMTS two networks (WLAN and WiMAX) are present and within the coverage of WiMAX, WLAN is present. The architecture consists of three users with three different applications such as video, voice and web browsing.

Figs.2, 3 and 4 show the throughput, delay and load in WLAN network. The maximum throughput of the network is found to be 0.2 Mbps this is because only less number of users is considered. Throughput of the network increases as the number of users increase. 


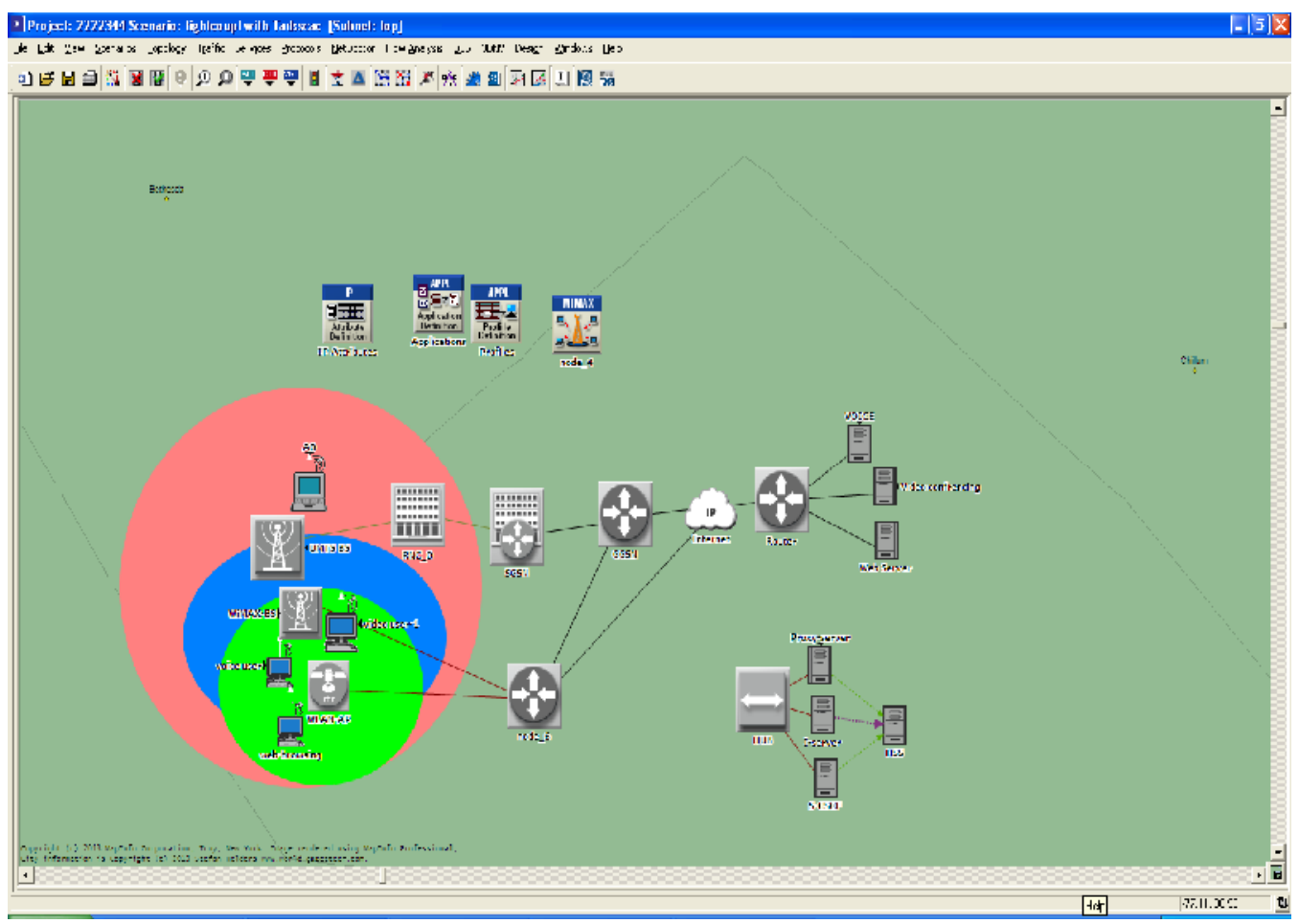

Fig.1 WLAN-WiMAX-UMTS architecture

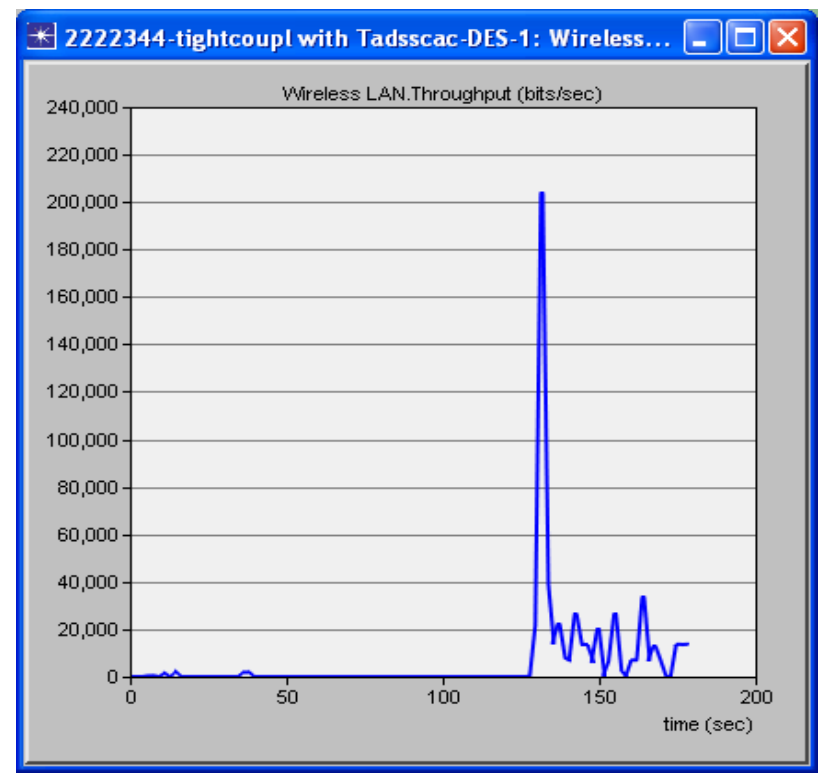

Fig.2 Throughput in WLAN 
International Journal of Wireless \& Mobile Networks (IJWMN) Vol. 5, No. 3, June 2013

Figs.5, 6 and 7 show the throughput, delay and load in UMTS network. Since the number of users considered in the architecture is minimum, the throughput obtained is less compared to the actual network throughput. The network throughput decreases based on loading conditions also. The delay in UMTS is less than WLAN network because UMTS is a circuit switched network whereas WLAN is a packet switched network.

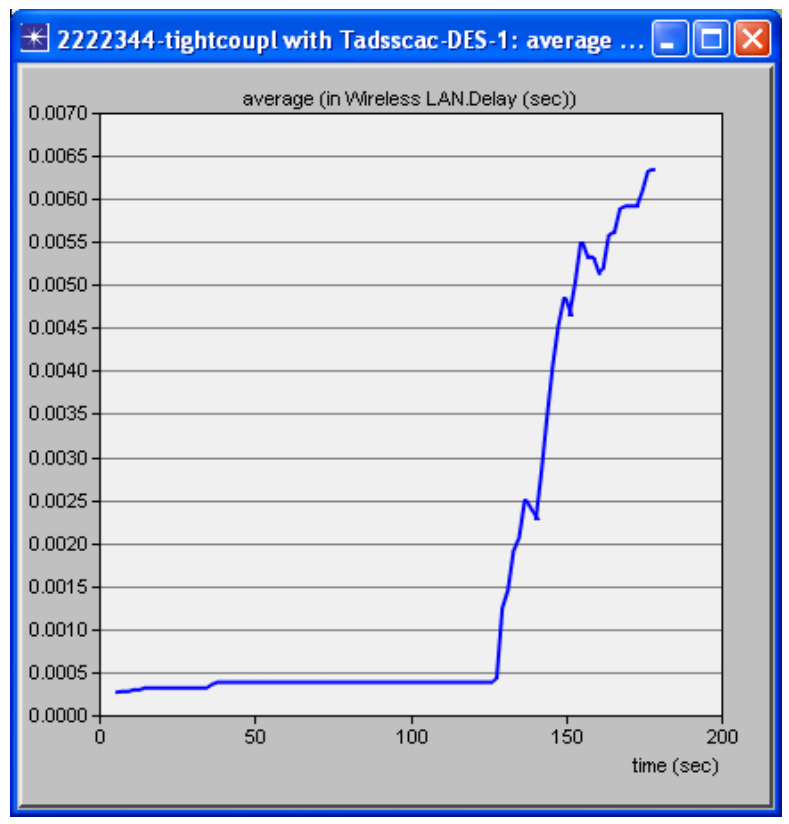

Fig.3 Delay in WLAN

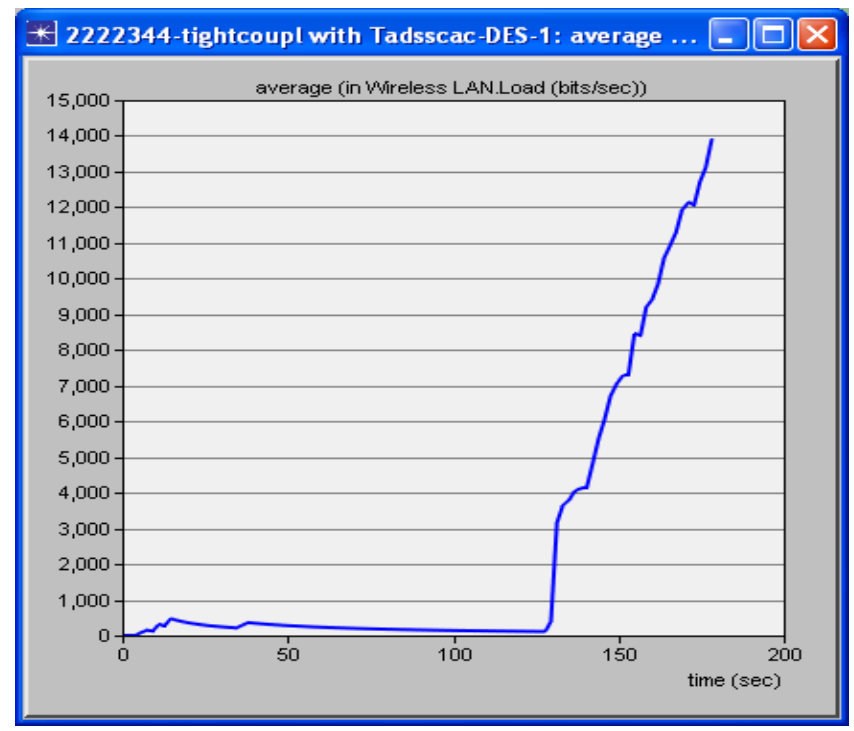

Fig. 4 WLAN Load 
International Journal of Wireless \& Mobile Networks (IJWMN) Vol. 5, No. 3, June 2013

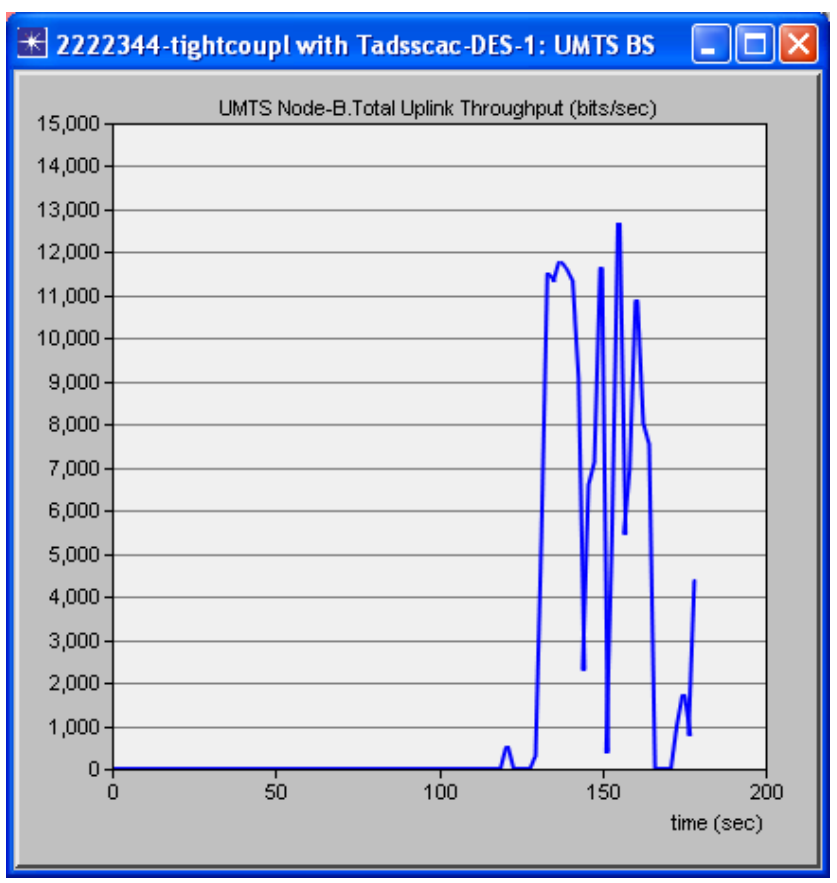

Fig.5 Throughput in UMTS

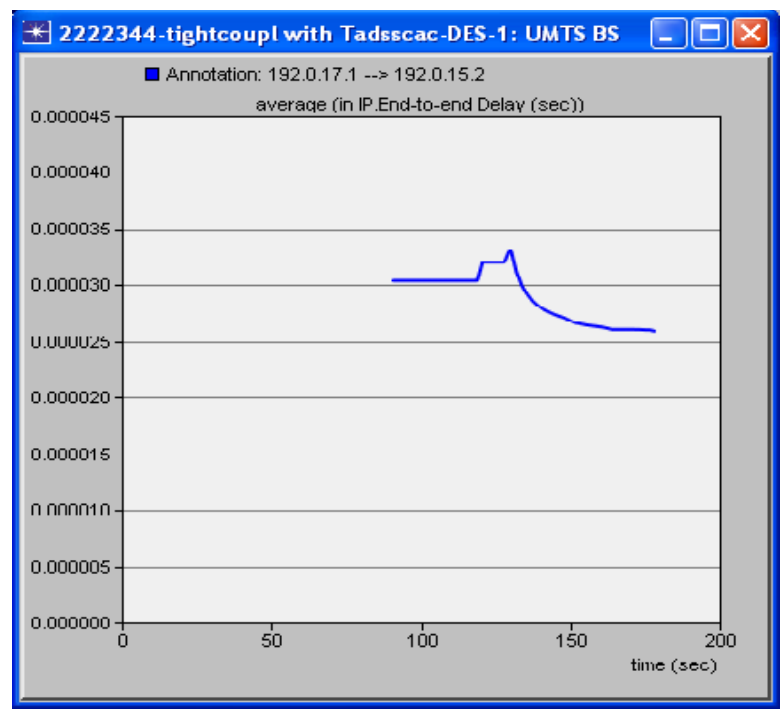

Fig.6 Delay in UMTS 
International Journal of Wireless \& Mobile Networks (IJWMN) Vol. 5, No. 3, June 2013

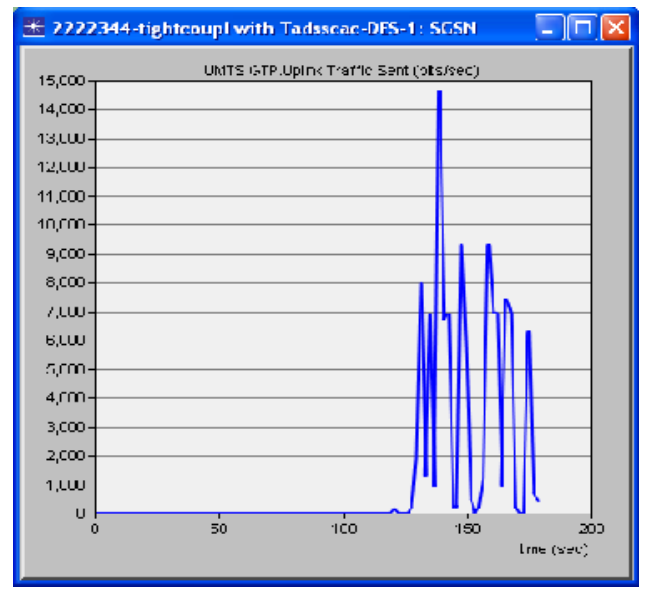

Fig.7 Load in UMTS

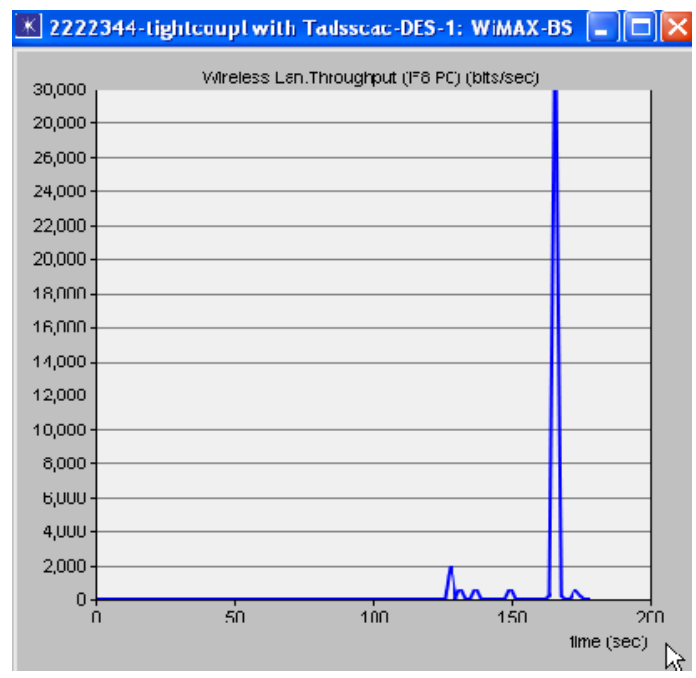

Fig.8 Throughput in WiMAX

Figs.8, 9 and 10 show the throughput, delay and load in WiMAX. Load created by users are less since three users are considered in this work that produces less throughput. 
International Journal of Wireless \& Mobile Networks (IJWMN) Vol. 5, No. 3, June 2013

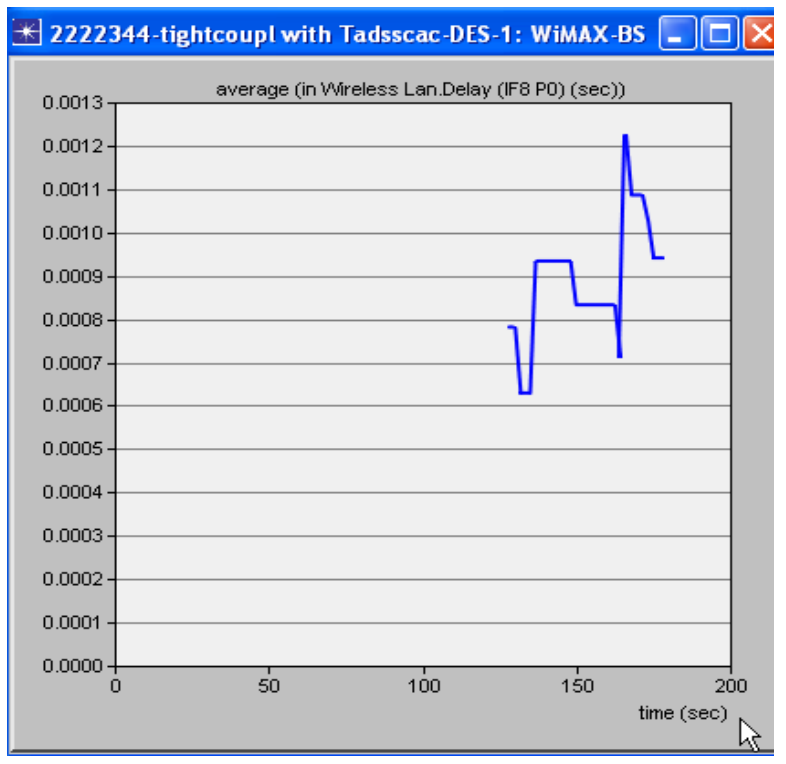

Fig.9 Delay in WiMAX

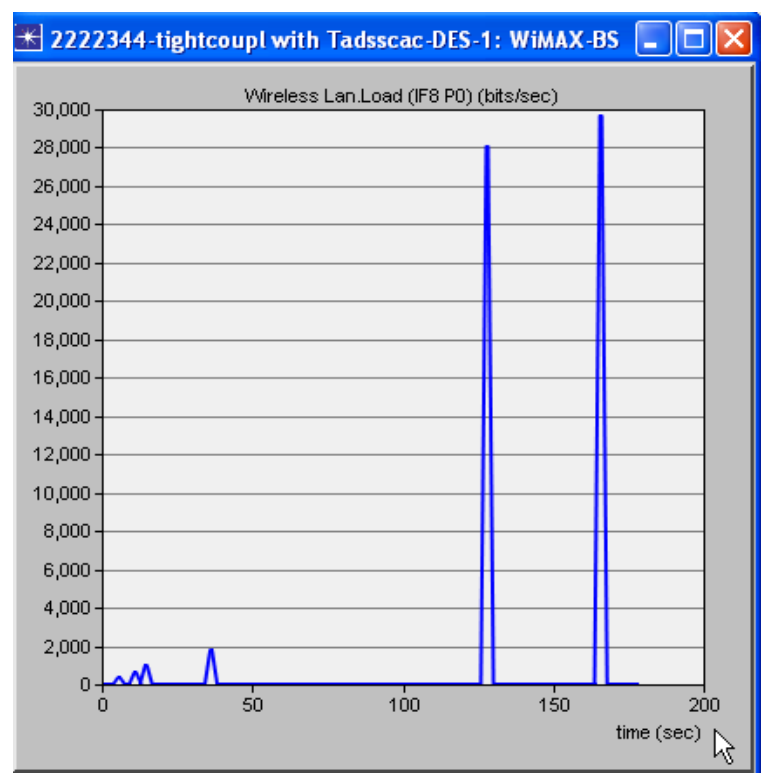

Fig.10 Load in WiMAX

Based on the metrics obtained in the integrated network architecture, network selection is performed. Initially user 1 (Voice) connected to WiMAX checks for the alternate networks (WLAN and UMTS) and calculates payoff in two networks. Fig.11 shows the payoff of user 1 in WLAN and UMTS. It is found that the payoff for user 1 in UMTS is maximum compared to WLAN. User 2 (Video) initially connected to WLAN checks for alternate networks and calculates payoff. The payoff for user 2 in WiMAX and UMTS is given in Fig.12. The figure shows that the payoff for user 2 in WiMAX is higher compared to UMTS. This is because user 1 already gets maximum payoff in UMTS. 
International Journal of Wireless \& Mobile Networks (IJWMN) Vol. 5, No. 3, June 2013

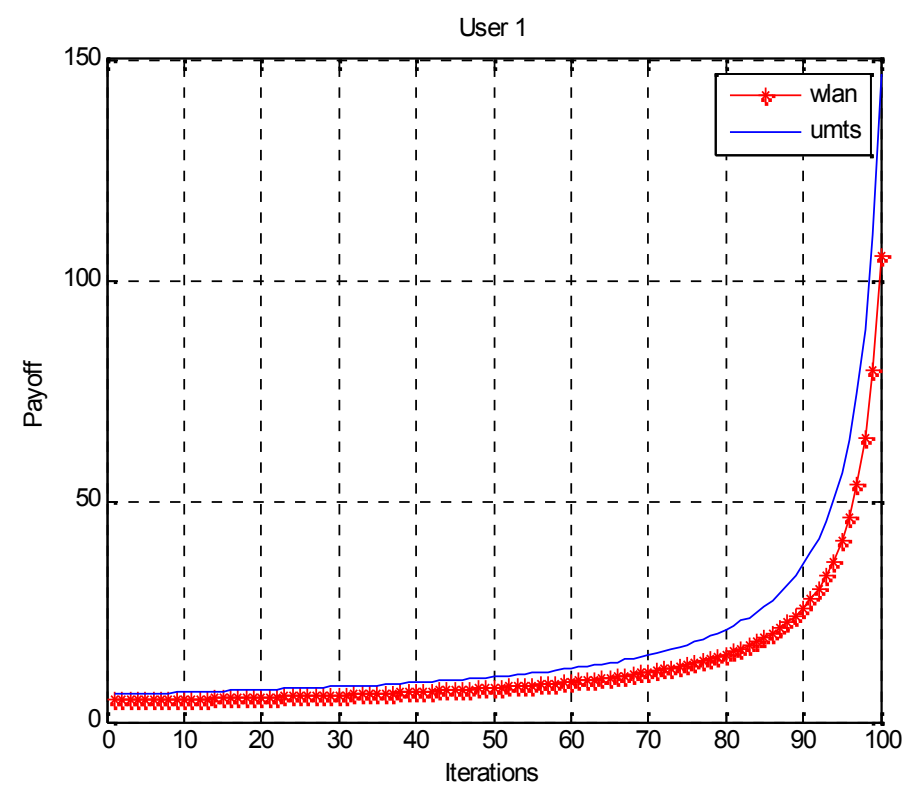

Fig.11 Payoff for User 1

User 3 (Web user) initially connected to UMTS checks for the alternate networks such as WLAN and WiMAX. Fig. 13 shows the payoff for user 3 in WLAN and WiMAX. The payoff for user 3 in WLAN is high when compared to WiMAX. This is because user 1 and 2 already gets maximum benefit in UMTS and WiMAX respectively.

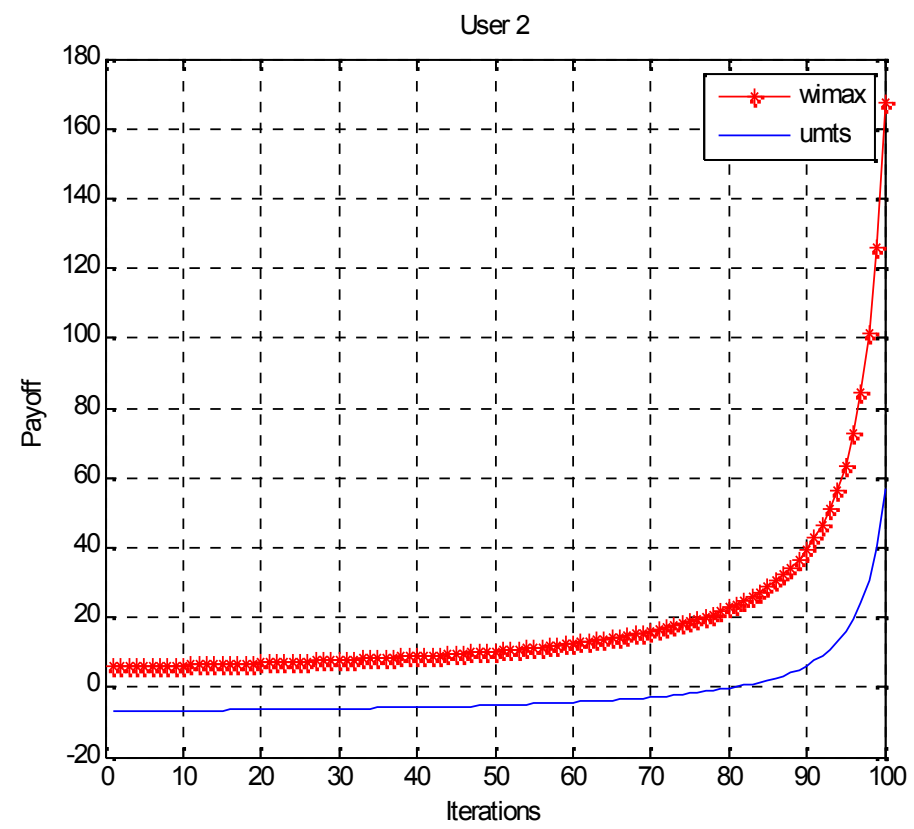

Fig.12 Payoff for User 2 
International Journal of Wireless \& Mobile Networks (IJWMN) Vol. 5, No. 3, June 2013

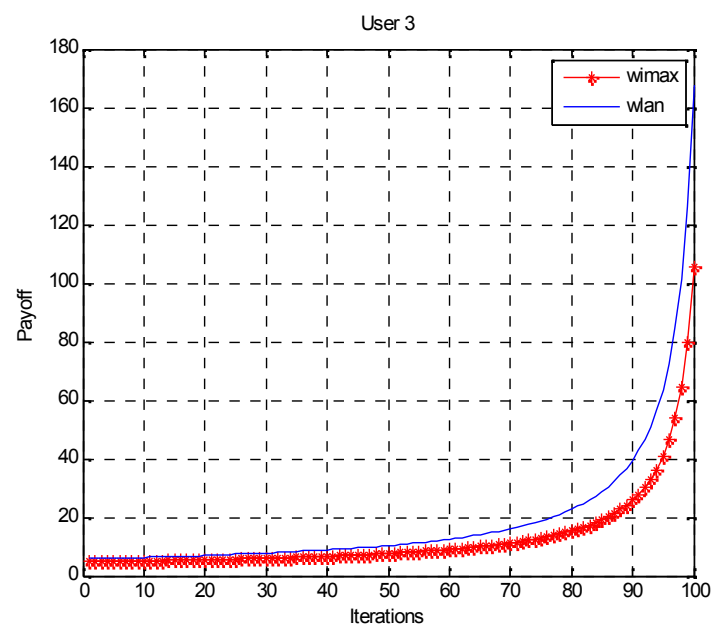

Fig.13 Payoff for User 3

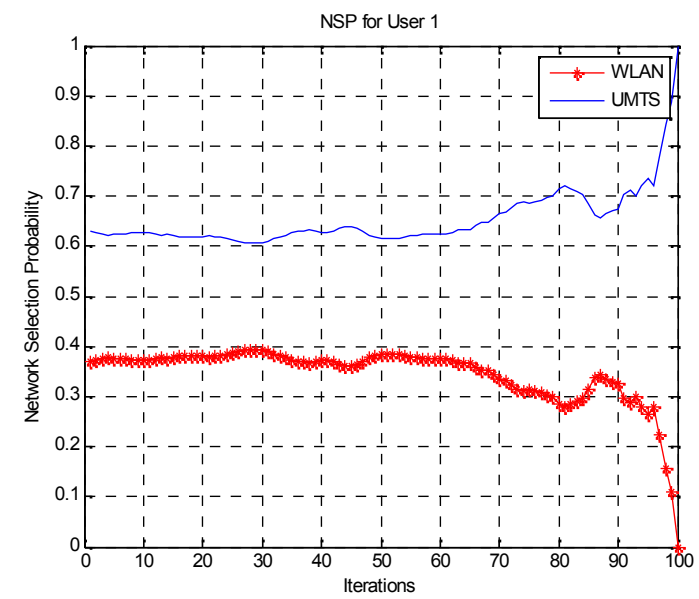

Fig.14 NSP for User 1

The NSP (Network Selection Probability) is determined based on the payoff as shown in Fig.14. Since the payoff for user 1 in UMTS is high, the NSP for user 1 in UMTS also high.Figs.15 and 16 show the NSP for user 2 and 3 respectively. Since payoff for user 2 in WiMAX is high so NSP for user 2 in WiMAX is also high. The maximum payoff for user 3 is attained in WLAN so NSP for user 3 in WLAN is high.

To implement the Quality of Experience (QoE) concept, users are classified as good and fair users. A good user is one who is ready to pay more for a particular service and expects high Quality of Service. On the other hand a fair user pays less for a service and compromises on the service quality. Fig. 17 shows user 1 and user 3 are fair users and user 2 is a good user. Even though user 1 gets maximum payoff in UMTS since the user is fair user, so user 1 selects WLAN. User 2 is a good user and selects WiMAX. User 3 is a fair user already connected in WLAN and remains in WLAN. 
International Journal of Wireless \& Mobile Networks (IJWMN) Vol. 5, No. 3, June 2013

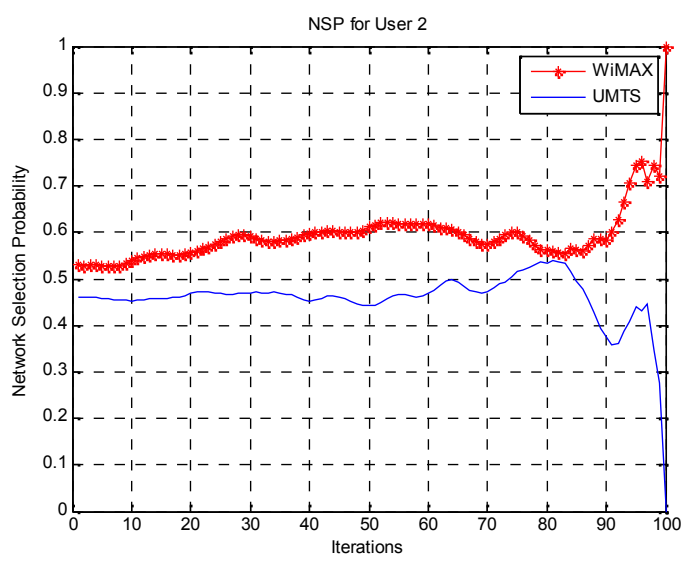

Fig.15 NSP for User 2

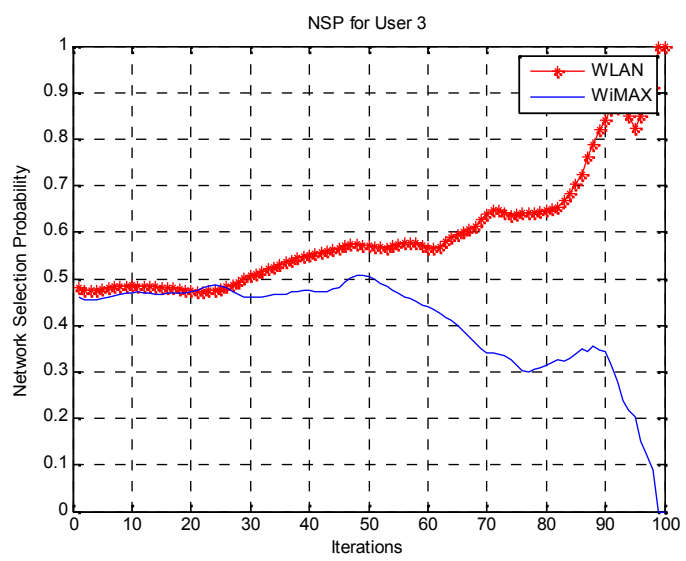

Fig.16 NSP for User 3

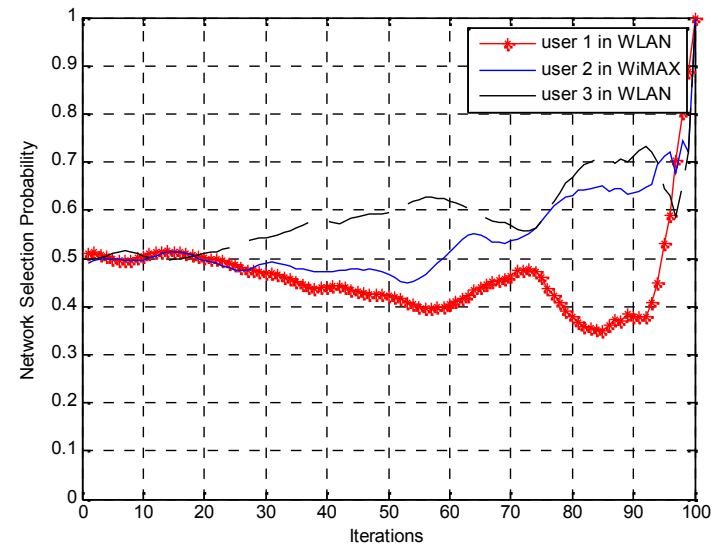

Fig.17 NSP for Users based on their budget 
International Journal of Wireless \& Mobile Networks (IJWMN) Vol. 5, No. 3, June 2013

\section{CONCLUSION}

Heterogeneous networks require intelligent network selection process for seamless connectivity. In this paper WLAN, UMTS and WiMAX networks are integrated using IMS based on SIP. Network selection was performed using the proposed Boltzmann Gibbs based CODIPAS-RL because this algorithm performs network selection faster than the existing Bush Mosteller based CODIPAS-RL. i.e., Boltzmann Gibbs based CODIPAS-RL takes 90 iterations whereas Bush Mosteller based CODIPAS-RL requires 200 iterations for selecting a network. Three users with three different applications such as voice, video and web were considered and the network selection was performed. The payoff for each user in three different networks are determined and based on the payoff, network selection probability was obtained.

\section{REFERENCES}

[1] D.E.Charilas and A.D. Panagopolous, "Multi access Radio Network Environments", In IEEE Vehicular Technology Magazine, vol. 5, no. 4, pp. 40-49, Dec. 2010

[2] Q.T.Nguyen-Vuong, Y.Ghami-Doudane and N.Agoulmine, "On utility models for access network selection in wireless heterogeneous networks," In IEEE Network Operations and Management Symposium (NOMS), 2008.

[3] H.Tembine and A.P.Azad, "Dynamic Routing Games: An Evolutionary Game Theoretic Approach," IEEE conference on decision and control European Conference, pp.4516-4521, Dec.2011.

[4] M. Nam, N.Choi, Y.Seok and Y.Choi, "WISE: Energy-efficient interface selection on vertical handoff between 3G networks and WLANs," Proceedings of IEEE International symposium PIMRC, pp.692-698,2004.

[5] Q.Y. Song and Abba S Jamalipour, " Network Selection in an Integrated Wireless LAN and UMTS environment using mathematical modelling and computing techniques", IEEE Wireless Communications Magazine, pp.42-48, June 2005.

[6] Manzoor Ahmed Khan, Hamidou Tembine and Athanasis V. Vasilakos, "Game Dynamics and cost of Learning in Heterogeneous 4G Networks", IEEE Journal on Selected Areas in Communications, vol. 30, no. 1, pp.198-214, Jan. 2012.

[7] Ramona Trestian, Olga Ormond and Gabriel-MiroMuntean, “ Game Theory- Based Network Selection: Solutions and Challenges”, IEEE communications surveys and tutorials ,pp.1-20, May 2011.

[8] F.Zhu and J.McNair, "Optimizations for vertical handoff decision algorithms," Proceedings of IEEE WCNC, pp.867-872, 2004.

[9] Mohammad SazidZaman Khan, ShaifulAlam and Mohammad RezaulHuque Khan, "A Network Selection Mechanism for Fourth Generation Communication Networks", Journal of Advances in Information Technology, vol. 1, no. 4, pp.189-196, Nov. 2010.

[10] D.Niyato and E. Hossain, "Dynamics of network selection in heterogeneous wireless networks: An Evolutionary Game Approach,” IEEE Transactions on Vehicular Technology, vol.58,no.4, pp.2008-2017, May 2009.

[11] Samson Lasaulse, H.Tembine, Game theory and learning for wireless networks: Fundamentals and applications, Elsevier,2011.

[12] P.Prabhavathi and L.Nithyanandan, "Network selection in wireless heterogeneous networks," Proceedings of IEEE International Conference on Communication and Signal Processing - 2013, pp. 1536-1539, April 2013. 
International Journal of Wireless \& Mobile Networks (IJWMN) Vol. 5, No. 3, June 2013

[13] D.Niyato and E. Hossain, "Dynamics of network selection in heterogeneous wireless networks: An Evolutionary Game Approach,” IEEE Transactions on Vehicular Technology, vol.58,no.4, pp.2008-2017, May 2009.

[14] H.Tembine, "Dynamic robust games in MIMO systems," IEEE Transactions on systems Man and Cybernetics, vol.99, no.41, pp.990-1002, Aug. 2011.

[15]

www.opnet.com

\section{Authors Biography}

L.Nithyanandan received Bachelor of Engineering from University of Madras in 1992, Master of Technology in 1999 and Ph.D. degree in 2006 from Pondicherry University. $\mathrm{He}$ is working as an Associate Professor of Electronics and Communication Engineering, Pondicherry Engineering College, Puducherry, India. $\mathrm{He}$ is a gold medallist in PG and has been awarded with chief minister Medal for his outstanding performance in PG. He has more than 22 publications in National /International conferences and journals. His areas of interest include Sensor Networks, Telemedicine, Spread Spectrum Techniques and wireless communication

V.Bharathi received Bachelor of Engineering from University of Madras in 1999, Master of Technology in 2003 and pursuing Ph.D. in Pondicherry University. She is working as an Associate Professor of Electronics and Communication Engineering, Sri Manakula Vinayagar Engineering College, Puducherry India. She has more than 13 publications in National/International conferences and Journals. Her areas of interest include Wireless Networks, Wireless Communicationand Signal Processing.

P.Prabhavathi received her Bachelor of Technology Degree from Pondicherry University in 2011 and Master of Technology degree in 2013 in Electronics and Communication Engineering. She is a gold medallist in UG. Her area of interest include spread spectrum wireless communication and networking.
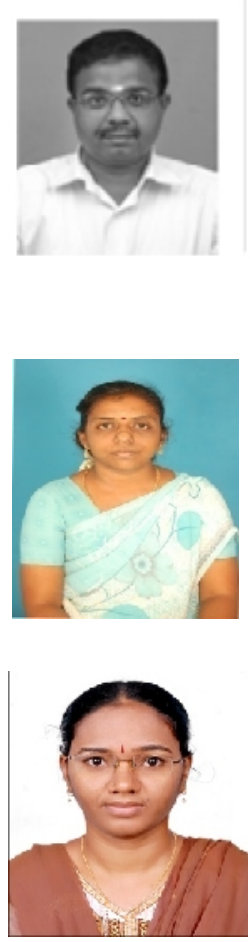
International Journal of Wireless \& Mobile Networks (IJWMN) Vol. 5, No. 3, June 2013

INTENTIONAL BLANK 